\title{
Collaboration, dialogue and expansive learning: the use of paired and multiple placements in the school practicum
}

\begin{abstract}
This study examines the way in which paired or multiple placements of student teachers in the school practicum can support learning through the promotion of collaboration and dialogue. It draws on data collected across six higher education institution (HEI)-secondary schools partnerships in England and focuses on a series of 20 case studies from one partnership. The results suggest that peer placements can support more expansive and deeper learning, especially where attention has been given to the structuring of the placements and the role of the mentor or cooperating teacher. In such cases there are also reciprocal benefits for the school.
\end{abstract}

Keywords: Initial Teacher Education; Collaboration; Peer learning; School Practicum; Mentoring

\section{Introduction}

Research in Initial Teacher Education (ITE) in many countries has highlighted the importance of the school practicum. However, systematic reviews of work in the field suggest a lack of detailed examination of the practices that are most effective in supporting student teachers' learning. In reviewing international research on organizational structures, management processes and conceptual frameworks, Bills et al. (2007) noted some evidence that student teachers benefitted from increased time in schools and from mentoring. Moyles and Stuart (2003), in their systematic review of which school-based elements of partnership were supportive of beginning teachers' professional development, found some evidence to support the importance of processes involving feedback and constructive dialogue and that placing two students together in a school could support the development of particular professional skills. However, both these reviews suggested the need for more explicit analysis of the nature of the structures and processes that influenced student teachers' learning during the practicum. The research presented in this paper seeks to respond to this important need.

The focus of our ongoing research has been on the efficacy of placing two or more students with the same subject specialism in the same school for the practicum. The first phase of this work, conducted across six HEI-schools partnerships over a four year period, involved collaboration between tutors, mentors and student teachers to study the characteristics of, and attitudes to, such placements, and the collaborative practices promoted. We adopted an iterative, mixed method approach, involving questionnaires, focus groups, structured interviews and observations of practice. The research initially drew on Maslow's hierarchy of needs (Maslow, 1970) in analyzing how far these placements had supported the higher order learning needs, 'self actualisation' and 'understanding and knowledge', through the use of particular collaborative 
practices. A broad range of such practices were identified, including joint planning, team teaching approaches, observing, assessing and evaluating (see Author, 2003; Author et al, 2004).

It was clear from this first phase of research that most student teachers were positive about the gains from paired placements, with the most common reasons cited relating to the emotional and psychological support provided. Gains in terms of fulfilling higher level needs, with students acting as 'critical friends' to support development in knowledge, skills and understanding of teaching and learning, were only sometimes in evidence. However, in such cases, mentors and tutors felt that student teachers made quicker progress and learning was enhanced (Author, 2003).

The importance of gaining a greater understanding of the interplay of policies and practices which are supportive of meeting higher level needs and hence enhance learning has driven the second phase of research presented here. Thus, this phase has involved detailed case studies of 20 paired or multiple placements in secondary schools (age 11-18) over a three year period. In analyzing these cases we have drawn on research literature and understandings from three broad areas: teacher education, professional development and mentoring; dialogic practices; and expansive learning within activity systems. The arguments for choosing these areas of focus are detailed in Section 2.

\section{Literature review and theoretical framework}

\subsection{Introduction}

It is important to set out the basis for drawing on the particular literature that follows at the start of this section in order to clarify its relevance to the study.

The review of the literature on teacher education in Section 2.2 below suggests that:

- teacher professional development can be enhanced by models involving collaborative practices;

- in ITE, the role of a mentor or collaborating teacher is very important in determining both the type and extent of the learning;

- peer placements can serve as a model to promote more effective collaborative practices.

In order to examine the collaborative practices within the peer placements two main frameworks have been deployed in the research: dialogism and expansive learning. Arguments for a focus on dialogism are presented in Section 2.3 and for expansive learning in Section 2.4.

\subsection{Teacher education, professional development and mentoring}

A review of models of Initial Teacher Education (ITE) across much of the world indicates that the dominant models have involved a significant HEI component - seen by many commentators as a 'theoretical' one (Hagger \& McIntyre, 2006) - and a school-based practicum. The most 
common practice has been to place a single student in a given subject area with a single 'cooperating teacher' or 'mentor' during the practicum. Thus Bullough et al. (2003, p.57), drawing on research from North America and Europe, noted that this pattern had 'remained little changed for 50 years'. However, in more recent times, parts of the world have seen an increased focus on school-based training programmes. Some developments have been driven by a concern to strengthen the links between schools and HEIs in order to bring theory and practice closer together, a notable forerunner of this being the Oxford Internship Scheme in England (Benton, 1990). Others have emerged through political challenges to the role of the HEI and governments seeking to take greater control over teacher education (Furlong, 2001; Sleeter, 2008; Zeichner, 2009). A consequence of these changes has been an increasing focus on a mentoring role in schools and, where HEIs remain involved, collaboration between HEI tutors, school-based mentors and student teachers. There is now a wealth of international literature examining policies and models of teacher education, much of which stresses the value of collaborative practices (see Menter, Hulme, Dely \& Lewin, 2010 and Zwozdiak-Myers et al., 2010, for systematic reviews of the international literature).

Arguments for collaborative approaches in ITE parallel those visible in the professional development literature, with reviews suggesting that sustained, collaborative approaches, embedded in contexts, involving peer support, as well as that from a more experienced mentor or coach, tend to be the most effective (e.g. Cordingley, Bell, Evans \& Firth, 2005). School improvement imperatives over many years have emphasized notions of collegial intelligence and teachers learning from each other (e.g. Joyce \& Showers, 1988; MacGilchrist, Myers \& Read,1997; Hodkinson \& Hodkinson, 2005) and researchers have stressed the importance of creating a culture of collaboration to support change (Fullan, 1999) and the power of distributed, collaborative leadership structures (Hallinger \& Heck, 2010). Thus persuasive arguments for the use of collaborative structures are visible at all levels in the system.

The common model of placing students singly in a given subject area in a school is at odds with the arguments for collaboration between peers. However, there has been a growing use of peer placement models in ITE in recent years. The innovative Oxford Internship Scheme (Benton, 1990) was one of the first in England to have paired placements in subjects at its heart and growth in the use of paired placements is reflected in emphasis given to this work by the Teacher Development Agency (Menendez \& Oulton, 2007) and the Higher Education Academy (Wilson $\&$ Bolster, 2011). Research from the US has added weight to arguments for the use of paired placements (e.g. Bullough et al., 2002; Bullough et al., 2003; Manouchehri, 2002; Nokes et al. 2008). Wang (2001), in comparing mentoring practice in the US, UK and China, notes that pairing arrangements can help develop the confidence of student teachers to bring forward ideas and hence avoid some of the problems that can arise when student teachers feel disempowered due to the structural hierarchies present in many schools (Hobson, 2009).

The models of collaboration suggested in the literature reflect the fact that much of the work on teacher education, professional development and mentoring is underpinned by a socio-cultural perspective, with a particular emphasis on the importance of discourse in the promotion of learning (Vygotsky, 1987). Many authors have stressed the importance of others in the development of a sense of self (e.g. Bandura, 1986; Maslow, 1970) and being encouraged to see practice 'through others' eyes' (Loughran, 2002, p.33) in developing the reflective practitioner 
(Schon, 1987). In line with this, the use of coaching (involving mutual observation and peer support) has long been identified as an effective tool for professional learning (Joyce \& Showers, 1988) and many authors (e.g. Hargreaves \& Fullan, 2000) have argued for the importance of the role of mentoring as a force for improving the profession.

Arguments for the importance of mentoring are leant weight by studies suggesting that mentoring quality is a more crucial factor in ITE than the nature of the route taken to accreditation. Looking particularly at US contexts, Feistritzer's (2008) review suggests that the most important factor of any programme is that it enables student teachers to work together in the classroom with mentors and the National Academy of Education (2009) study argued strongly for the value of programmes involving mentors working with student teachers in a sustained school practicum. Indeed, such arguments have underpinned the Professional Development Schools (PDS) model in the US (Holmes Group, 1990; Utley et al., 2003).

While roles described as 'mentoring' and 'coaching' are now common in teacher education, reviews of the literature show that these role descriptions are often used interchangeably and the emphasis given to particular aspects of the roles varies across jurisdictions (Fletcher and Mullen, 2012). Maynard and Furlong (1993) identified three broad models of mentoring that have been prevalent in ITE: the apprenticeship, competency and reflective practitioner models. The competency model in particular, based on clearly defined standards, has been a strong feature of mentoring in England since the 1990s. While this model has attempted to draw on research into effective practice, its dominance has been criticized. Furlong et al. (2000) note that the concentration on standards and competences has tended to undermine notions of reflective practice, devalue critical evaluation and hence limit the depth of professional knowledge development.

Maynard and Furlong (1993, p.82) noted that the reflective practitioner model suggested the need for mentors to position themselves more as 'co-enquirers' into practice. Hargreaves and Fullen (2000, p.55), in critiquing some of the then dominant practices, argued that mentoring should move from 'hierarchical dispensations of wisdom to shared inquiries into practice'. Such arguments have been developed further in recent years. In the US a call for more inquiry-based approaches has been linked to the need for developing teachers who are able to work in a variety of settings and communities and be prepared to meet the diverse needs in such settings (DarlingHammond, 2006; Sleeter, 2008). Zeichner (2006), in reviewing practices in the US and elsewhere, argues for some key actions in ITE. Of particular relevance to this research is his stress on the need for careful planning and integration of the practicum within ITE programmes and the development of more transformative mentoring models within strengthened school and community roles. It is clear that mentors will need to be committed to developing reflective and transformative practices if they are to embrace the potential of the collaborative practices that are facilitated by the peer placements of student teachers.

Nokes et al.'s (2008) study of the use of paired placements noted that 'where student teachers planned or taught collaboratively they reported engaging in extensive talk about teaching practices' (p.2174). This finding, together with our own previous research, suggests that this is an important area for further research and development and leads us to the second theoretical perspective of our research: dialogic practices. 


\subsection{Dialogic practices}

We have drawn on the dialogic concept of language (Alexander, 2004; Bakhtin, 1981; Holquist, 1990) to examine the interactions between student teachers and between student teachers and their mentors. In particular, the idea that 'communicative acts only have meaning, only take on their specific force and weight, in particular situations or contexts' (Dentith, 1995 p3). This analysis suggests moving away from ITE structures where the dialogue about the theoretical underpinning of practice is separated from the practice itself. Furthermore, it accords with evidence that student teachers are often unable to transfer ideas across contexts and may, in a new context, face opposition from others who were not involved in discussions in the original context (Ellis, 2010; Haggar \& McIntyre, 2006). As Lave and Wenger (1991) argue, learning is situated in forms of social co-participation, as skills are developed through actually engaging in a process, which they describe as 'legitimate peripheral participation'. Such situated learning is employed by Roth and Tobin in their use of co-teaching, involving cooperating teachers and university tutors working alongside student teachers, and their work provides some important evidence for the efficacy of such approaches (e.g. Roth \& Tobin, 2001). Indeed, ideas on 'praxeology' and the development of theory through praxis (Roth \& Tobin, 2004) provide an important perspective to this research and have informed some of the collaborative approaches promoted for use in the practicum.

The application of Bakhtinian thought on dialogue in the classroom and staffroom has guided our thinking on how the models of collaborative practice promoted through peer placements may support dialogic approaches in the school practicum. Alexander (2004 p.27), in examining dialogic teaching in classroom contexts, has identified indicators of dialogic teaching as:

- $\quad$ collective: teachers and children address learning tasks together, whether as a group or as a class;

- $\quad$ reciprocal: teachers and children listen to each other, share ideas and consider alternative viewpoints;

- supportive: children articulate their ideas freely, without fear of embarrassment over 'wrong' answers; and they help each other to reach common understandings;

- cumulative: teachers and children build on their own and each other's ideas and chain them into coherent lines of thinking and enquiry;

- purposeful: teachers plan and steer classroom talk with specific educational goals in view.

He goes on to state that 'The dialogic principle...is all pervasive. So if it is valid for children's learning, it is no less valid for the learning of adults, including teachers themselves' and 'to commend dialogic learning for the classroom but not the staffroom is likely to be counterproductive as well as inconsistent. The dialogic principle is more effectively promoted if it is also exemplified' (ibid, p.37).

In furthering this application of dialogic principles in this second phase of the research we have modified the indicators developed by Alexander (2004) to focus on the learning of the student 
teachers, with a primary focus on student teacher-student teacher interactions. The modified indicators are:

- collective: pairs of student teachers deciding on tasks (either separately or together), undertaking tasks (at least in part together) and evaluating tasks (together);

- $\quad$ reciprocal: students teachers listen to each other, share ideas and consider alternative viewpoints;

- $\quad$ supportive: student teachers articulate their ideas freely, without fear of embarrassment over 'wrong' answers; and they help each other to reach common understandings;

- cumulative: student teachers build on their own and each other's ideas and chain them into coherent lines of thinking and enquiry, drawing on the support of cooperating teachers;

- purposeful: student teachers plan school-based learning opportunities, drawing on the support of cooperating teachers, with specific learning goals in view.

For any given activity, the mentor or cooperating teacher may be involved from the beginning, as part of the process; after the process and any discussion between the pair of students; or not at all. However, over a sequence of activities the mentor's role is likely to be a critical one and the extent to which the mentor sees themselves as part of a reciprocal learning process will be an important factor in terms of their engagement in the processes and the resultant impact on learning. The way in which a mentor engages with the student teachers provides a model which may work with or against dialogic learning. Critical to this, it is suggested, will be an openness to the idea of joint inquiries into practice, an acceptance that dialogue is an essential component of such inquiries and that meanings are located in a relativistic world and can therefore be neither fixed nor absolute (Bakhtin, 1981; Holquist, 1990). Thus, while the main use of the dialogic indicators was concerned with dialogic practices between the student teachers, attention was also focused on their dialogue with the mentors or cooperating teachers.

\subsection{Expansive learning}

In examining the complexity of the system involving the student teachers working together with mentors in the schools, we have used a third theoretical perspective, arising from the field of Cultural Historical Activity Theory. The key idea here is that 'activity in the process of a genuine dialogue is not a simple transformation of a co-interlocutor in accordance with the aims or plans of another; it includes the aims or plans of another; it includes the self-realization of the participants at the same time' (Lektorsky, 1999, p.68). Thus, in developing a model of 'expansive learning', Engeström (1987) has stressed the importance of questioning as the first action of such an expansive learning cycle. The model he proposes seeks to develop from the abstract (where abstract refers to the simplest unit of an interconnected system) to the concrete, 'from individual subjects questioning the accepted practice...into a collective movement or institution' (Engeström, 1999a, p.382). The cycle continues to reflect voices from a variety of perspectives and viewpoints and in its development takes account of past cycles and hence the importance of historicity (Engeström, 1999b) in the epistemic actions contained in the cycle. 
The expansive learning cycle developed by Engeström (1999b) involves the following epistemic actions: 1 Questioning; 2 Historical and empirical analysis; 3 Modeling the new solution; 4 Examining the new model; 5 Implementing the new model; 6 Reflecting on the process and 7 Consolidating the new practice. This learning cycle is often applied to large systems but it can also be used at a micro level, such as here, where we apply it to student teachers' professional learning. For example, in learning how to assess pupils' work, the first two stages of the cycle require student teachers being involved in raising questions and enquiring into current assessment practices, finding out how these practices arose and examining the research evidence to support their use. Stages 3-5 suggest that the student teachers work closely with mentors and others within schools, as part of an interconnected system constantly trying to improve its assessment practices in support of learning. The reflection on the outcomes of implementing particular assessment approaches in Stage 6 then leads to Stage 7, where the student teacher consolidates the use of those approaches deemed to be effective. The typification of expansive learning presented here clearly contrasts with the experience of student teachers who can often feel that they are at the bottom of the pecking order (Hobson, 2009) and unable to question prevailing orthodoxies, with the attendant risk that there is very limited development in epistemological or ontological thinking (Ellis, 2010; Whitehead and Fitzgerald, 2006). At its worst, the lack of critical engagement embedded in some contexts may simply lead to the perpetuation of ineffective practice (Feiman-Nemser, 2001).

We draw on the expansive learning cycle in our analysis of the data in order to see how far the peer placement model has helped to support the processes suggested by the cycle and hence expand learning. The presence of two or more students in a department would seem to provide the potential to promote questioning and enquiry through the interaction between the student teachers, as well as giving more empowerment to question the status quo through acting together rather than alone. This accords with some of the arguments for dialogic practice made earlier.

\subsection{Linking theoretical perspectives}

The value of these three theoretical perspectives in examining work in the practicum is lent further support by the work of Korthagan, Loughran and Russell (2006), who analyzed the effective features of teacher education programmes in Australia, Canada and the Netherlands. This analysis led to the development of an initial framework of seven fundamental principles to guide teacher education programmes. These principles suggest the need for programmes where student teachers, mentors and university-based tutors work closely together, with an emphasis on inquiring into practice and viewing 'knowledge as a subject to be created rather than as a created subject' (p.1027). As part of this, the fifth principle, that 'learning about teaching requires an emphasis on those learning to teach working closely with their peers' (p.1032), provides strong support for the peer placement model.

Finally, lying behind many of the ideas explored in each of the three broad literature areas outlined above are views about student teachers working together with others, including more experienced mentors, in communities of inquiry in order to construct what Cochran-Smith and Lytle (1999) describe as 'local knowledge of practices'. The emphasis here is on processes and models of working. Cochran-Smith (2009) positions such arguments within a theory of teacher education for social justice. The focus of our research has been on promoting student teacher 
learning. However, we believe that a focus on peer learning and processes of inquiry within communities of practice provides a framework in accord with a commitment to equity and social justice.

\section{Research design}

This research was conducted in one of the six HEI-schools partnerships in England where the initial research studies described in the introduction took place. The students were all on one year, secondary (age 11-18) Post-Graduate Certificate of Education (PGCE) courses, covering a range of subject specialisms. While the students are all required to have a first degree in their relevant subject, some come straight from undergraduate courses and others later in life after other career experiences. In England, students on such courses are required to spend a minimum of 120 days in school, two-thirds of the 180 day total. At the university they are taught as a cohort, with most teaching taking place in small subject or cross-subject groups. Underpinning the teaching approach is a commitment to developing reflective practice. There are strong links between the university and partnership schools, with committees made up of representatives from schools and university faculty responsible for developing and monitoring the partnership. Faculty tutors visit students in school on a minimum of four occasions during their practicum placements. The schools involved are very diverse in terms of: indices of social deprivation (e.g. level of poverty); city/ rural locations; sizes; and ethnicity profiles.

It is also important to note that the partnership does not impose requirements of how placements operate. Thus some pairs operate in schools with separate timetables, while others have one or two shared groups or even largely shared timetables. A broad range of possible collaborative practices are shared with the student teachers and mentors, including various approaches to team teaching, but there is no imposed expectation of using particular approaches. In terms of mentoring, this also varies, with some having one mentor and others separate mentors within the paired placement.

The background and overall aims of the research are outlined in Section 1. Here we focus on the case study approach adopted in this phase of the research. Each case study consists of two or more student teachers placed together with one or more mentors for the practicum. Seventeen of the cases involved a pair of students, two cases were threes and one was a four. The aim of the case studies has been to examine:

1. the characteristics of the placements and collaborative practices that have supported and deepened learning;

2. the nature of the dialogue taking place, both between the student teachers and between the student teachers and their mentors, and its perceived impact on learning;

3. evidence for elements of the expansive learning cycle;

4. the role of the mentor in supporting collaborative processes designed to deepen learning;

5. the reciprocity of the learning relationship.

The use of case studies in our work fits into the tradition of a 'collective case study' (Stake, 2005), with an interpretivist stance taken in examining the use of peer placements in a number of different contexts. While one case study can provide a rich analysis of a particular instance of the use of peer placements, the range of variables in the schools within the partnership is large. Thus, 
the collective case study approach was adopted with the aim of drawing out understandings to provide insights that might resonate with a variety of contexts. The sampling approach is purposive in the sense that it allows examination of cases where student teachers in the same subject area are placed together in schools that have agreed to work with more than one student teacher. Within this sample, it is also opportunistic in terms of both student teachers and mentors volunteering to take part.

The depth of the case studies varied. In all 20 cases data was collected through: field notes, including some audio recordings of discussions with student teachers $(\mathrm{N}=16)$ and mentors $(\mathrm{N}=10)$; examination of teaching practice portfolios and semi-structured interviews with students $(\mathrm{N}=40)$ and mentors $(\mathrm{N}=18)$ following the school practicum. More in-depth case studies were conducted with six pairs of student teachers in six schools, involving observations of paired teaching episodes, supported by video and follow up discussions of the video sequences. The choice of the six pairs was a furthering of purposive sampling to allow probing of particular collaborative practices that arose during the practicum. They were selected on the basis of evidence collected during early school visits suggesting that these pairs were making use of a variety of collaborative practices.

The interviews with students involved questions concerning: organization of mentoring (shared or separate mentors); meeting patterns; timetabling (the extent to which the student teachers were given shared classes to teach); the forms of collaboration that took place; perceptions of the benefits and impact on their learning; the extent of the support provided by peers; overall comments on the efficacy of the placement. The interviews with the mentors included similar questions, with additional questions concerning their reasons for taking a pair and possible impacts on their own learning.

The observations and discussions of the videos of the teaching sequences focused on: evidence of collaboration through planning; approach taking place within the lesson; reasons for the approach; perceptions of the value of the form of collaboration; evaluation of the lesson and their learning from the experience; involvement of the mentor in the process; overall view and impact on future planning.

The main analytical approach was content analysis. This involved two broad, parallel elements. One element was a grounded approach to the analysis of responses to the questions concerning the practices, attitudes and views expressed concerning peer learning, collaboration and mentoring. The other element was an analysis of all data sources for evidence of the dialogic indicators and elements of the expansive learning model discussed earlier. Within each case study this required identifying instances of each dialogic indicator or element of expansive learning from: the field notes and discussions on the school visits (plus video evidence for the indepth case studies); reports, reflections and lesson evaluations in the teaching practice portfolios; and the end of course interview data. It is important to stress that the process was not linear. Thus constant comparison techniques within the grounded approach (Corbin and Strauss, 2008) were adopted, with data sources within a case study being revisited in the light of emerging evidence across cases. Wherever possible, the outcomes of the analysis were discussed with the participants to check on the trustworthiness of the conclusions being drawn. 
Insider research of this kind raises some difficult ethical issues. The research was conducted within the ethical guidelines of the British Educational Research Association (BERA, 2004). In approaching the student teachers, all were asked if they would volunteer but care was taken to make it clear that it would not count against them if they declined. This approach was also taken with mentors and schools, with appropriate attention to confidentiality issues and opportunities to withdraw from the research at any stage. A number of other related positionality issues also arise. One concerns the power imbalances between the tutors, mentors and student teachers, especially given that the researchers were tutors on the courses. Issues of students telling us what we wanted to hear had to be considered seriously. It was not possible to use collection methods completely separate from the researchers, as the approach was built into course structures and the data collection was often linked to normal school visits. This meant a continued emphasis on making it clear that there were no expectations of what was supposed to be said and the use of researchers independent of the research to do interviews where this was possible.

Further reflexivity issues arise from the closeness of the researchers to the case studies. A key component of ensuring trustworthiness in the research was to include forms of mutual collaboration, both in terms of the collection of the data and its analysis. The data collection methods included those embedded in the course, as well as observations and interviews that enabled different researchers to be involved. Collaboration was furthered in terms of analysis of the data. This included examining the same data together and/or separately, discussing interpretations with mentors and students teachers and cross checking data from participants with the documentary evidence.

\section{Results and Analysis}

\subsection{Overview}

The analysis of the dialogical practices and expansive learning evident in the case studies is presented here in the light of the grounded analysis. The presentation of the data reflects the collective case study approach. Thus the emphasis is placed on general themes that have emerged from a variety of contexts. The conceptual frameworks of dialogic practice and expansive learning serve as the basis for presenting the results, reflecting aims 2 and 3 of the research highlighted at the start of Section 3, as well as the overall focus on peer placements. The analysis and discussion then draws on the characteristics of the particular case study contexts, reflecting aims 1, 4 and 5. The quotes presented are those from the interviews, obtained either on school visits during the practicum or after its completion. The emphasis has been on using voices from across the cases studies in the space available, so the majority of student teachers and mentors quoted, or serving as specific exemplars, are used just once.

\subsection{Dialogic Learning}

The results provide strong evidence that those student teachers who felt secure in their critical friendship were operating in ways which were in accord with indicators of dialogic learning. Critical friendship was examined by looking for instances of students describing mutual respect and acting in ways that involved open discussion of development needs. Many such instances 
were evident in 16 of the case studies. The illustrations below serve to exemplify particular practices and, where offered as general examples, they are chosen because they are 'typical' in the sense that they were strong features in many of the case studies.

Indicators 1 and 2 - collective and reciprocal

There was clear evidence that the students who were operating collectively, in a reciprocal manner, perceived there to be considerable gains. There were many references to the lower level emotional support provided. Typical of the phrases were:

'great to have someone to evaluate lessons with...sometimes I thought it'd been a disaster ...they cheered me up'; 'a shoulder to cry on'; 'helped me to feel good about what I had achieved'.

However, many examples of higher order gains were also identified. Typical of gains in knowledge and understanding were:

'in terms of subject knowledge, yes, loads [of gains] ....we shared a group and divided tasks... at the end of this I felt much more confident with Shakespeare and like to think [they] had learnt in other ways...deciding [tasks] together took time, but we gained in the long term..';

'we had a difficult group...they could be a nightmare and we wanted to see if different strategies might have different effects...you know, trying out positive behaviour management strategies or assertiveness techniques... having two made this much easier and I felt less, somehow, exposed...it was good to be able to talk about it together immediately afterwards...our mentor was great but often too busy to get involved... at the end we both could manage the group on our own...it was a really good experience... ';

'I think we are better prepared than some of our group who were on their own...we planned so much together...it took a bit of time to work out what we were doing but then it was really good... assessment was a good example, we each marked some [assignments] and then swapped...it really helped us to get a sense of the [National Curriculum] levels'.

The issue of considering alternative views came across strongly from some students:

'I tended to think that I needed everyone to be quiet...I got worried when things were getting noisy...he made me think more about what was going on ...other strategies as well...I developed a much bigger [sic] variety of teaching strategies... ';

'We argued a lot! [strong emphasis] ... but it was really good, well mostly [laughs] ...it made me read more, I even went back to some lecture notes and ended up changing my mind about some learning theory stuff...it was through arguing about it that I came to see the value...I'm a bit more open to things now, perhaps...'. 
Overall, examples of collective and reciprocal work were found in relation to development of nearly all of the standards areas required for Qualified Teacher Status (QTS) in England, including subject knowledge, planning, monitoring and assessment and class management.

\section{Indicator 3 - supportive}

In addition to the emotional and psychological support, many of the students felt a sense of being liberated from pressure by the more equal peer relationship and the removal of the formal assessment role seen to be inevitably linked to working with an experienced teacher. Thus students talked about the nature of the dialogue being more open when they spoke with each other and their willingness to take risks:

'...it's more difficult to admit mistakes or express worries with your mentor...you don't want them to think that you're weak ...I know this may be silly but they do judge you, don't they?';

'...I'd never tried role play but my partner was really into it...I don't think I'd have tried it without trying it out together...hadn't listened much to the theory at uni[versity] .....we argued a lot afterwards...I think we converted others in the department to try it out... ';

'Don't get me wrong, she [the mentor] was great but, you know, really busy...she did her job, more than she was supposed...but joint planning, well, takes ages doesn't it...we could do it, well, make time and then we got so much out of it... she gave us great feedback on this... said she wished she had the time to do some...'.

The students also felt more empowered to talk to their mentors through having collaborated in advance and/or being together in mentor meetings:

'It was much easier to raise things when it seemed to come from both of us';

'...we were able to prepare better for meetings... made me more confident...even used Vygotsky to explain why I'd done something... he seemed to be impressed, even though he did say he'd not used theory much in his teaching...';

'Our mentor was excellent, such a great teacher... and she was so up to date, even seemed to know all the theories...I felt a bit overwhelmed at the start but talking together [with my peer] helped me to feel more confident to talk to her...I know it's stupid to feel inferior with a degree like mine but, anyway, I did at the start...at the end I wasn't like that at all...it really helped [being in a pair] ....'.

Mentors who commented agreed that the supportiveness of students being in a pair helped:

'They came well prepared and ready to engage...it made my life much easier';

'...to be honest, it's an advantage having two...they sort things out themselves and help each other...'; 
'I'm a convert [to pairing] ...I worried about time but have found it's better...they support each other well...helps them to learn...'.

The other data sources also suggested that the mentors had usually recognized and valued the way that the student teachers had supported each other.

Indicators 4 and 5 - cumulative and purposeful

Where evidence was strong in relation to the previous three indicators there was usually evidence of a cumulative effect or chaining of thinking and enquiry. However, this was not always structured and rarely felt by the students to be an explicit part of the process. In reflecting back on their placements, students were often able to see a bigger picture and regretted not having planned more prior to and during the placement. It is important to stress here that there was little pressure on the students in the cohort to take advantage of the possible collaborations and only limited discussion, either with them or their mentors, in many of the schools. Typical of comments on the impact of limited planning and expectations on collaboration were:

'We could have done so much more...I think tutors should talk to us about this more... and mentors, ours didn't seem to know about it... ';

'Don't make it compulsory but say more about this to mentors and schools...I know that a friend was in a school that did this and she says it went well... a bit of pressure would be OK if people know why it's happening... ';

'I'd do lots more now if I went back... I really want to try and work collaboratively in my new job...'.

Many of the exemplars outlined for the first three indicators can also be applied to indicators 4 and 5. However, an important point that arose here was the contrast between those student pairs who had at least one shared teaching group in a school and those who did not. Purposeful use of the pairing in the school tended to be less prevalent in the six case studies where there was no teaching group in common. Further, entirely separate mentoring of the student teachers also limited dialogic processes. The mentor data showed that in about half the case studies the mentor had not been involved in supporting student teachers planning together. In probing this issue through the interviews, most mentors saw its value but it had not happened due to lack of time or thought given to the opportunities.

\subsection{Expansive Learning}

The analysis identified instances where all aspects of the expansive learning cycle were visible. For space reasons, just one instance of this is summarized below as an example. It describes two student teachers' approach to looking at the organization of a shared teaching group, in particular the positioning of the desks in the classroom. Historically desks had always been kept in rows. The reason given by the cooperating teacher was 'they need to be like this so they'll concentrate 
... and I can keep an eye on them'. The summary is annotated in relation to the expansive learning cycle. The names are pseudonyms.

Mel and Mark argued about the organization of the group in the classroom. Both were critical of the accepted arrangement and the idea that it had to be like this. They felt it made a lot of teaching difficult [1 Questioning]. In looking at why it was like this, their analysis included reference to control issues, prevailing models of teaching which tended to be more grouped in the transmission mode and difficulties with the shape of the room and moving the desks. They further noted that many rooms in the school were like this and appeared to have been so for some time. They knew that the cooperating teacher felt that students worked better sat in rows [2 Analysis]. In seeking a solution to this problem Mel produced some notes she'd made on classroom organization and its impact on learning. They discussed the relationship between different arrangements and the activities suited to such arrangements. After considerable analysis and playing with the furniture in the room they came up with three different arrangements that could be tried without major time involved in changing things round. Each arrangement was linked to different teaching and learning strategies [3 Modeling]. After a brief impasse the cooperating teacher agreed to let them try it out in one lesson [4 examining the model] and, following some positive outcomes, this led to a series of lessons using a variety of arrangements and variations of who sat where, at what point changes took place and for how long [5 implementing]. The cooperating teacher noted some positive benefits at times alongside problems and Mel and Mark met with him to share their own reflections on the process, which were largely positive [6 Reflecting]. This led to an agreement to continue to use changed arrangements for particular purposes in the short term, with rows serving as the starting base in most cases. This was then continued [7 Consolidating].

The brief summary possible here does not do justice to the complexity of some of the discussions and processes, but all aspects of the learning cycle could be identified. Also important to note was that neither of the student teachers felt that a solution had been reached, so the cycle continued with new questioning which took them in other directions related to meeting individual needs. The cooperating teacher indicated that he intended to try aspects of the new arrangements after the students had left. Thus reciprocal learning was identified in this case.

The cooperating teacher from the above example confessed that his opposition to other arrangements had been 'pretty simplistic'. This lack of depth to thinking about practices came across in elements of several of the case studies. However, it was clear that there were often issues in terms of the 'official discourse' taking place in the schools that led to limitations in the critical engagement. The exemplars below, each involving pairs of students, are illustrative of the way national policies and local perspectives acted against more expansive learning:

'We decided this time that we didn't want to share our objectives with the class...or link to the previous lesson. There were reasons for this [goes on to discuss the idea of "hiding" the objectives and checking at the end that the pupils had "picked them out" and "seen the point"] but our mentor said we had to, everyone had to, or the lesson 
couldn't be satisfactory...senior management in the school said that Ofsted [Office for Standards in Teacher Education - the government's inspection service] wanted to see this...';

'We decided to let the pupils pick the variables themselves and plan their [scientific] investigations...we looked at some of the ideas from the [university] session on this and found a couple of other things on the web...but we were told that they must do the 'concentration' [of the acid] 'cos it got good results...this didn't make any sense... we were told one thing at uni[versity] and another at school...our mentor said that uni[versity] tutors were out of touch with what was needed to get the pupils good marks...';

'We'd looked at different ways of differentiating in [university] sessions...we wanted to let the pupils pick how they wanted to learn...motivation was low in the class and we thought this was worth a try...our class teacher told us this wouldn't work as they [the pupils] couldn't be trusted, so we had to try something else'.

The first two examples illustrate how schools' interpretation, right or wrong, of national policies and curriculum can close doors to learning, the third links back to the fixed/simple answer problem of the cultural context of the school. All three are examples where the questioning and analytical phases of the expansive learning cycle were completed but any attempt to model was prevented. However, there were also instances where the official discourse seemed to remove the questioning and analysis phases altogether and the model being implemented was then largely external to the student teachers. Here the process became trying out 'givens' and then evaluating how well they had gone in order to make the 'givens' go better. As an example, in considering the opening parts of a lesson, the discussion concerned 'how to do starters' ('starters' being a particular feature stressed by advisors and inspectors in England during this period) rather than 'how can lessons be introduced?'; 'why might particular methods be used in particular circumstances?'; 'what currently happens?'; 'what are the advantages of each in given situations?' etc.

In situations where the official discourse, either at a school level or from a national perspective, was extremely pervasive, mentors said relatively little about their own learning. However, there were instances of mentors who felt constrained and trapped by the situation:

'I know that it's better to be more open to ideas...it's time, SATs [the Standardized Assessment Tasks] and all that...we just have to do things sometimes to get them through...';

'We have to do this at the start and end of each lesson, so students need to do it as well...it's on the [performance management] sheets...'.

There were many comments from mentors in this vein, even though they were not specifically asked to comment about such issues. 
In contrast to these situations where more expansive thinking lacked support, were those where mentors were active in promoting inquiry. An illustration of this is provided by a case where the mentor took the lead in planning an investigation into the use of particular differentiation strategies with parallel groups of pupils. This required reorganizing timetables to allow the student teachers to work together as part of an enquiry involving questioning of current practices, researching data on alternatives and the trialing of particular approaches within team teaching arrangements. What was notable in the observational data and discussions with the student teachers and mentor that focused on this work was the extent to which all three spoke about their learning and their analysis of the process they had been through. As the mentor commented:

'We need to do more of this.... being able to work with them like this has meant trying out new ideas.... I think I've probably benefitted as much as them'.

In 12 of the case studies mentors mentioned at least some aspect of them learning from their work with pairs of student teachers. This accords with a number of other studies noting reciprocal benefits (e.g. Carrington, 2004; Gilles \& Wilson, 2004; Hastings, 2004; Hobson, Ashby, Malderez \& Tomlinson, 2009).

\section{Discussion and implications of the study}

The research indicates that the use of peer placements in the practicum can support the development of higher level thinking and criticality. However, the research has highlighted a number of important issues in the structuring and enactment of teacher education within the school practicum, some that arise whether or not students are placed together with peers. Within each case study there is a complex interplay between the policies and practices of the school, themselves influenced to varying extents by outside pressures, the orientations of the school to the school practicum and the approach taken by the mentor. In discussing the outcomes and implications of the study we seek to draw out some of the contrasts and similarities that can be discerned from the collective case studies and hence highlight issues of policy and practice that need to be considered if the potential benefits of paired placements are to be realized.

Central to the arguments presented in Section 2 has been the implication that deepening student teachers' learning requires critical engagement with practice and learning models that are open and expansive in their scope. Models that are characterised by hierarchies of knowledge and transmission modes will tend to limit development. In addition, where strong imbalances of control exist between those in positions of power and others in the system, learning opportunities will be lost. It has not been possible to provide a detailed breakdown of each of the case studies drawn on in this paper. Nor has any attempt been made to classify each case study in relation to variables such as degrees of collaboration or the nature of the culture or the attitude of the mentor. There are far too many such variables, and, in any event, mentors were found collaborating extensively in planning within contexts where a collaborative culture was judged to be lacking. However, there were some commonalities that could be picked out from comparing cases and it is these that are highlighted below.

The issue of 'official discourse', used in the Bakhtinian sense (Bakhtin, 1981), is raised in the analysis, as references to this were evident across the case studies. In some examples there was a 
clear distortion in the balance of what Bakhtin has termed the 'science of ideologies, the studies of differential relations between " $I$ " and others .... the main task of such a science [as being] to conceive the reality of both the individual and society without doing conceptual violence to the status of either' (Holquist, 1990, p.50). Thus if the control mechanisms used to impose 'official discourse' are strong then 'everyone is compelled to speak the same language (outer speech is all)' (ibid, p.52) and communication and thought is suppressed. This leads to the possibility of important considerations not being entertained, as evidenced by examples from our data presented earlier. This can be understood in terms of the strength of centralized control of the curriculum and the normative risks associated with some of the standardized external and internal evaluation systems (Wilkins \& Wood, 2009). Thus, the background to ITE in England is one of a closely prescribed set of standards and a strong centralized inspection regime. The school curriculum itself is also laid out at a national level, with assessment arrangements that are largely external and nationally determined. There have also been a plethora of national strategies designed to raise standards. This has all led to the dominant discourse in English schools becoming increasingly concerned with the implementation of policies imposed at national level (Ball, 2008; Maguire and Dillon, 2007). In the light of this, the unwillingness of some mentors and schools to consider alternative learning strategies and embrace the kinds of collaborative engagement suggested as critical to transforming practice can be easily understood. However, models of ITE that are built within professional, discursive collaborative communities provide a potential to challenge reductionist, normalization of ITE (Furlong et al., 2000) and peer placements do seem to provide some support for challenging official discourse, especially where mentors and schools are open to this and see its value in supporting more transformative development.

The flip side to a dominance of outside influences concerns the resistance of individuals to change, with 'inner speech' predominating. The research shows that where student teachers may be unwilling to engage with new ideas, working with a peer can help them to consider issues more fully and hence restore balance to the discourse. Interestingly, sometimes the school, under pressure from national imperatives, was keen to look at new ideas and the student teachers were also willing to seek to model such ideas in practice, but the mentor was the one resistant to 'outer speech'. Again, the evidence showed that working with a peer did sometimes help student teachers to raise issues with mentors and, in some cases, overcome the resistance to examining new practices.

We noted at the start that the structuring of some ITE courses, with inputs in the HEI still seen by many as 'theory' and in the schools as 'practice', can act as a barrier to learning. The case studies showed that this separation of theory and practice still remained firmly embedded in the language of some of the mentors. Ellis (2010) has argued that 'a fundamental problem with England's design for pre-service teacher education is an impoverished version of "experience" in school' due to 'designs for teacher education (as framed by policy) [relying on] an acquisition view of learning and a view of knowledge as a thing to be transferred (experienced teacher to beginner)' (p.106). A key argument in this critique is one of the impact of power differentials between tutors, mentors and student teachers on forcing out dialogue and debate. Experience becomes 'learning how to fit in', which he describes as 'a strange kind of experience that allows no history and, therefore, no future' (p.110). This bleak analysis alludes to the absence of the first two stages of Engström's (1987) expansive learning cycle. It is interesting in that in trying 
to develop alternative approaches Ellis (2008, p.116) draws on Engström's work on activity systems and 'Change Laboratories' (Engeström, 2007), with models that involve 'inquiry by student teachers, teachers and university-based teacher educators'. Our research suggests that peer-learning approaches can help support such models.

The preparation of the student teachers and mentors for working in peer placements remained quite limited for this sample. The interview data suggests that more careful preparation, clarity of purposes and raised expectations would be welcomed. The evidence in most settings, in most countries, is that even where HEI-school partnerships are regarded as strong, the HEI remains in the driving seat in development. Haggar and McIntyre (2006) note that this is not conducive to high level understanding and ownership of the processes. They suggest that HEIs need to develop approaches which bring them closer to schools and work more closely with mentors. As Zeichner (2006, p.334) suggests: the practicum needs to be 'as carefully planned as any other college or university course' and 'closely integrated with the rest of the teacher education programme'. While this and earlier studies (Author, 2003; Nokes et al., 2008) have shown that benefits accrue even without clear preparation for mentors, this study has also shown that it is important for mentors to understand their role. Further, the expectations on how mentors will need to operate in these roles imply careful consideration is given to their selection and, in particular, the dispositions required. Again, the selection often seems to be lacking in considered thought, as it is not viewed as an important role within school structures (Menter, Hulme, Dely and Lewin, 2010; Zwordiak et al., 2010). This was reflected to a large extent in many of the case studies.

\section{Concluding comments}

The reviews by Moyles and Stuart (2003) and Bills et al. (2007), discussed at the start of this article, suggested a need for further research into the structures and processes taking place in the school-based aspects of ITE. This research has sought to respond to this need. It has focused in particular on the use of paired placements in the school practicum, as there has been some evidence (e.g. Nokes, et al., 2008) that such placements can help enhance learning. It has sought to bring together understandings of teacher education, professional development and mentoring, ideas on dialogic teaching and learning, and notions of expansive learning, as a means to analyse practice within the peer placements. In so doing it has also highlighted a number of policy and practice issues that arise whether or not paired placements are employed. Thus, in general terms, the research suggests that learning in the practicum is likely to be promoted where:

- faculty tutors and mentors are open to working together with student teachers on inquiring into practice, rather than simply accepting prescribed solutions;

- there is a collaborative culture, within the school as a whole and, most importantly, in the subject department;

- there is a shared understanding between the school, the HEI and the student teachers of the planned processes;

- time is made available for mentors to fully engage with their role;

- engagement with teacher education is seen as integral to the school.

It also suggests that: 
- more attention needs to be given to the selection and professional development of mentors in schools;

- HEIs need to be committed to supporting faculty tutors to work closely with schools within collaborative structures.

These more general issues raise policy challenges for those responsible for teacher education across international contexts. In England, the Coalition Government's plans for teacher education (DfE, 2010), now being put into practice, emphasize the importance of school-based training but see this as largely concerned with learning craft skills from 'experts'. Like England, many other countries have seen an increased centralized control of teacher education (Sleeter, 2008; Zeichner, 2009) and this, too, has often been accompanied by a shift in emphasis to school-based training. Zeichner's (2006) review of practice internationally, noted earlier, stressed a need for carefully planned practicum placements, with collaboration and reflective practice at their heart, as part of a process of transforming learning. In such placements there needs to be openness to critical discussion and a willingness to be prepared to try out new ideas and challenge the kinds of official discourses found to be so prevalent in many contexts. Our research showed that peer placements helped to promote inquiry but that opportunities to expand learning were also highly dependent on mentors who were also willing to challenge orthodoxies, resonating with Cochran-Smith's (1991) call for placing beginning teachers with reformorientated, experienced teachers willing to 'teach against the grain'.

In terms of the specific focus of the research, it is clear that peer placements have much potential to support learning in the school practicum. Where the opportunities for collaboration are embraced, dialogic processes are promoted and learning is likely to be more expansive. However, this requires careful planning within HEI-school partnerships. Working together with peers at this beginning stage of a teacher's career also serves as a positive model for continuing professional development and has reciprocal benefits for mentors. More significantly, it has the potential to support the development of sustained learning cultures in schools.

\section{References}

Alexander, R. (2004). Towards Dialogic Teaching: Rethinking classroom talk, Cambridge: Dialogus.

Author (2003) [details removed for peer review]

Author et al (2004) [details removed for peer review]

Bakhtin, M. M. (1981). The Dialogic Imagination. Austin: University of Texas.

Ball, S. (2008). The education debate. Bristol: Policy Press.

Bandura, A. (1986). Social foundations of thought and action: a social cognitive theory. Englewood Cliffs, London: Prentice-Hall.

Benton, P. (Ed.). (1990). The Oxford Internship Scheme: Integration and Partnership in Initial Teacher Education. London: Calouste Gulbenkian Foundation.

Bills, L, Briggs M., Browne A., Gillespie., H, Gordon, J., Husbands, C., Shreeve, A., Still, C. \& Swatton, P. (2007). Structures, management and process in initial teacher education: a systematic review. In Research Evidence in Education Library. London: EPPI-Centre, Social Science Research Unit, Institute of Education, University of London. 
British Educational Research Association (BERA). (2004). Revised ethical guidelines for educational research. Retrieved 12.04.12 from http://www.bera.ac.uk/publications/ethical-guidelines.

Bullough, R.V., Young, J., Birrell, J.R., Clark, D.C., Egan, M.W., Erickson, L., Frankovich, M., Brunetti, J. \& Welling, M. (2003). Teaching with a peer: a comparison of two models of student teaching, Teaching and Teacher Education, 19, 57-73.

Bullough, R.V., Young, J., Erickson, L., Birrell, J.R., Clark, D.C., Egan, M.W., Berrie, C. F., Hales, V., \& Smith, G. (2002). Rethinking field experiences: Partnership teaching vs. single-placement teaching, The Journal of Teacher Education, 53, 68-80.

Carrington, G. (2004). Supervision as a reciprocal learning process. Educational Psychology in Practice 20, 31-42.

Cochran-Smith, M. (1991). Learning to Teach against the Grain. Harvard Educational Review 61, 279-310

Cochran-Smith, M. (2009). Toward a Theory of Teacher Education for Social Justice. In A. Hargreaves, Lieberman, A., Fullan, M. \& Hopkins, D. (Eds.), Second International Handbook of Educational Change. Dordrecht: Springer

Cochrane-Smith, M. \& Lytle, S. (1990). Research on teaching and teacher research: The issues that divide. Educational Researcher, 19, 2-11

Corbin, J. \& Strauss, A. (2008). Basics of Qualitative Research. London: SAGE

Cordingley, P., Bell, M., Evans, D., \& Firth, A. (2005). The impact of collaborative CPD on classroom teaching and learning. Review: What do teacher impact data tell us about collaborative CPD? In Research Evidence in Education Library. London: EPPI-Centre, Social Science Research Unit, Institute of Education, University of London.

Darling-Hammond, L. (2006). Powerful teacher education. San Francisco: Jossey-Bass

Dentith, S. (1995). Bakhtinian thought. New York: Routledge.

DfE (2010). The importance of teaching: the schools white paper. London: The Stationery Office

Ellis, V. (2008). Exploring the contradictions in learning to teach: The potential of developmental work research. Changing English - Studies in Reading and Culture, 15, 53-63.

Ellis, V. (2010). Impoverishing experience: the problem of teacher education in England. Journal of Education for Teaching, 36, 105-120.

Engeström, Y. (1987). Learning by expanding: an activity-theoretical approach to development research. Helsinki: Orienta-Konsultit.

Engeström, Y. (1999a). Innovative learning in work teams: Analyzing cycles of knowledge creation in practice. In Y. Engeström, R. Miettinen, \& R.-L. Punamaki (Eds.), Perspectives on Activity Theory (pp. 377-406). New York: Cambridge University Press.

Engeström, Y. (1999b). Activity theory and individual and social transformation. In Y. Engeström, R. Miettinen, \& R.-L. Punamaki (Eds.). Perspectives on Activity Theory (pp. 19-38). New York: Cambridge University Press.

Engeström, Y. (2007). Putting Vygotsky to work: The change laboratory as an application of double stimulation. In H. Daniels, M. Cole, \& J.V. Wertsch, (Eds.), The Cambridge companion to Vygotsky (pp.363-82). Cambridge, UK: Cambridge University Press.

Feiman-Nemser, S. (2001). From preparation to practice: Designing a continuum to strengthen and sustain teaching. Teachers College Record 198, 1013-1055. 
Feistritzer, E. (2008). Building a Quality Teaching Force: Lessons Learned from Alternate Routes. Upper Saddle River, NJ: Pearson Merrill Prentice Hall.

Fletcher, S. J. \& Mullen, C. A. (Eds.) (2012). The Sage Handbook of Mentoring and Coaching in Education. London: SAGE.

Furlong, J. (2001). Reforming teacher education, re-forming teachers: accountability, professionalism and competence. In R. Phillips \& J. Furlong, (Eds.). Education, Reform and the State: Twenty-Five Years of Politics, Policy and Practice (pp. 118-135). New York: RoutledgeFalmer.

Furlong, J., Barton, L., Miles, S., Whiting, C. \& Whitty, G. (2000). Teacher education in transition: re-forming professionalism? Buckingham: OUP.

Gilles, C \& Wilson, J. (2004). Receiving as well as giving: mentors' perceptions of their professional development in one teacher induction programme, Mentoring and Tutoring, 12, 87-106.

Hagger, H. \& McIntyre, D. (2006). Learning Teaching from Teachers: realizing the potential of school-based teacher education. Maidenhead: Open University Press.

Hallinger, P. \& Heck, R. H. (2010). Collaborative leadership and school improvement: understanding the impact on school capacity and student learning. School Leadership \& Management, 30, 95-110.

Hargreaves, A. \& Fullan, M. (2000). Mentoring in the New Millenium. Theory Into Practice, 39, $50-56$.

Hastings, W. (2004). Emotions and the practicum: the cooperating teachers' perspective. Teachers and Teaching: theory and practice, 10, 135-148.

Hobson, A. J. (2009). On being bottom of the pecking order: beginner teachers' perceptions and experiences of support. Teacher Development, 13, 299-320.

Hodkinson, H. \& Hodkinson, P. (2005). Improving schoolteachers' workplace learning. Research Papers in Education, 20, 109-131.

Holmes Group (1990). Tomorrow's schools: Principles for the design of professional development schools. East Lansing, MI: Author.

Holquist, M. (1990). Dialogism: Bakhtin and his world, New York: Routledge.

Joyce, B.R. \& Showers, B. (1988). Student achievement through staff development. White Plains, New York: Longman.

Korthagen, F., Loughran, J. \& Russell, T. (2006). Developing fundamental principles for teacher education programs and practices. Teaching and Teacher Education, 22, 1020-1041.

Lave, J. \& Wenger, E. (1991). Situated Learning: Legitimate Peripheral Participation. Cambridge: Cambridge University Press.

Lektorsky, V. A. (1999). Activity theory in a new era. In Y. Engeström, R. Miettinen, \& R.-L. Punamaki (Eds.). Perspectives on Activity Theory (pp. 65-69). New York: Cambridge University Press.

Loughran, J.J. (2002). Effective Reflective Practice: in search of meaning in learning about teaching. Journal of Teacher Education, 53, 33 - 43.

MacGilchrist, B., Myers, K., \& Reed, J. (1997). The Intelligent School. London: Paul Chapman.

Maguire, M. \& Dillon, J. (2007). Education policy and schooling. In J. Dillon \& M. Maguire (Eds.), Becoming a Teacher (pp. 29-41). Buckingham: Open University Press.

Manouchehri, A. (2002). Developing teaching knowledge through peer discourse, Teaching and Teacher Education, 18(6), 715-737.

Maslow, A. H. (1970). Motivation and Personality. New York: Harper and Row. 
Maynard, T. \& Furlong, J. (1993). Learning to teach and models of mentoring. In D. McIntyre, H. Hagger \& M. Wilkin, Mentoring: Perspectives on school-based teacher education (pp. 69-85). London: Kogan Page.

Menendez, J. \& Oulton, C. (2007). Report on TDA's Pilot Multiple Placement in Mathematics and Science 2007. London: TDA.

Menter, I., Hulme, M., Dely, E. \& Lewin, J. (2010). Literature Review on Teacher Education in the $21^{\text {st }}$ Century. Edinburgh: Education Analytical Services.

Moyles, J. \& Stuart, D. (2003). Which school-based elements of partnership in initial teacher training in the UK support trainee teachers' professional development? In Research Evidence in Education Library. London: EPPI-Centre, Social Science Research Unit, Institute of Education, University of London.

National Academy of Education (2009). Teacher Quality: Education Policy White Paper. S. Wilson (Ed.). Washington DC: Author.

Nokes, J. D., Bullough, R. V., Egan, W. M., Birrell, J. R. \& Hansen, J. M. (2008). The pairedplacement of student teachers: An alternative to traditional placements in secondary schools. Teaching and Teacher Education, 24, 2168-2177.

Roth, W-M \& Tobin, K (2001). Learning to teach science as practice. Teaching and Teacher Education, 17, 741-762.

Roth, W-M \& Tobin, K. (2004). Coteaching: from praxis to theory. Teachers and Teaching: theory and practice, 10, 161-179.

Schon, D.A., (1987). The Reflective Practitioner: how professionals think in action. London: Basic Books.

Sleeter, C. (2008). Equity, democracy and neoliberal assaults on teacher education. Teaching and Teacher Education, 24, 1947-1957.

Stake, R. E. (2005). Qualitative Case Studies. In. N. K. Denzin and Y. S. Lincoln (Eds.), The SAGE Handbook of Qualitative Research (Third Edition) (pp. 443-466). London: SAGE.

Utley, B. L., Rhodes, L. K. \& Basile, C. G. (2003). Walking in two worlds: master teachers serving as site coordinators in partner schools. Teaching and Teacher Education, 19, 515528.

Vygotsky, L.S. (1987). Thought and word. In R.W. Rieber \& A.S. Carlton (Eds.), Problems of general psychology, Vol. 1. The Collected Works of L. S. Vygotsky. New York: Plenum Press.

Wang, J. (2001). Contexts of mentoring and opportunities for learning to teach: a comparative study of mentoring practice. Teaching and Teacher Education, 17, 51-73.

Whitehead, J. \& Fitzgerald, B. (2006). Professional learning through a generative approach to mentoring: lessons from a Training School partnership and their wider implications. Journal of Education for Teaching, 32, 37-52.

Wilkins, C. \& Wood, P. (2009). Initial teacher education in the panopticon. Journal of Education for Teaching 35, 283-297.

Wilson, P. And Bolster, A. (2011). New models of teacher education: collaborative paired placements. Bristol: ESCalate.

Zeichner, K. (2006). Reflections of a university-based teacher educator on the future of collegeand university-based teacher education. Journal of Teacher Education, 57, 326-340.

Zeichner, K. (2009). Teacher Education and the Struggle for Social Justice. London: Routledge.

Zwozdiak-Myers, P., Cameron, K., Mustard, C., Leask, M. \& Green, A. (2010). Literature review: analysis of current research, theory and practice in partnership working to 
identify constituent components of effective ITT partnerships. TDA/Brunel University, West London. Retrieved on 06.07.11 from

http://www.scribd.com/doc/29847198/T35416-Literature-Review-Final-February-2010. 